\title{
EDITORIAL
}

\section{Why Examine Buffer Organizations in Higher Education?}

Those of us who were not on the Planning Committee for the Fifth Annual Conference on Higher Education in Edinburgh in late August 1991 found that we owed that committee a vote of thanks, as attending the various sessions on buffers in higher education was a very rewarding experience. As it turned out, people arrived from most parts of the world with very different notions of what constituted 'buffers'; organizations nominated ranged from the traditional grants committees 'in the middle' to such variations as university governing boards, rectors' conferences and research councils.

The very variety pointed to a justification for the conference, as clearly some taxonomic sorting out had to be undertaken. Some participants felt that 'intermediary bodies' was a more inclusive term, as they suggested that not all intermediary bodies acted as 'buffers'.

In offering the following papers from the Conference, we have purposely not tried to narrow the terrain or to exclude papers for having adopted one definition or another. Instead, it was the feeling of the Editorial Committee that this initial effort to examine buffers should show the full range of complexity, leaving it to later studies to sharpen and refine the focus.

The Keynote Address by Guy Neave details the broad-ranging perspectives on buffers in many countries. Neave offers several different criteria by which buffer organizations could be classified: whether they allocate resources, plan and coordinate or merely bring institutions together in a forum to discuss common issues; whether they have jurisdiction over one, two or multiple sectors in higher education; and whether, in their origin, they were created 'top down' or 'bottom up'. Since Neave's paper was not available in advance of the Conference, none of the other authors took up the challenge implicit in Neave's paper to create a worldwide taxonomy of buffer organizations based on his criteria.

Instead, the other Conference papers included several that dealt with the nature of buffers in general, including Frackmann, El-Khawas and Spoonley, and most others focus on specific countries. Four papers look at the British system followed by four papers dealing with United States buffers. There are also papers on buffers in Germany and the United States, on the Netherlands, Austria, Sweden, Turkey and the Canadian provinces of Quebec and Ontario. In addition four papers examine research councils in Germany, Netherlands, Italy and Brazil.

After reading all the papers in this volume, one may feel that most buffers are flawed in one respect or another. But then one has to continue the intellectual journey to ask what else would take the buffer's place? Although several Canadian provinces, other than the two represented by papers here, have eliminated their buffers and moved to direct governmental administration of the universities, the relatively small number of universities involved and the relative recentness of these changes preclude making any sweeping judgements on such examples. The 'folk wisdom' traditionally has been that direct governmental administration of any complex set of universities and colleges will work over the long haul not to have been to the advantage of either the government or the universities.

And recent experience in Eastern Europe may suggest that the opposite condition, of near-total university autonomy, is no more workable over the long haul. Universities in the Czech and Slovak Republics, after years of totalitarian governmental controls, have been given great freedom in their recent national law. Yet observers could see that sooner or later the newly independent institutions would have to start learning to work together. Clearly, then, it seems to many of us who try to think about relations between universities/colleges and governments that buffers of one kind or another may represent the lesser evil. It was no less a personage than Winston Churchill who remarked that democracy was the worst form of government except any other that had been tried!

Most of the following papers have been severely cut to fit into the limits of this special issue. If readers are interested in a given topic or author, they are urged to write to the authors in question for the full paper delivered at Edinburgh.

Finally, it remains to thank Elaine El-Khawas, John Sizer and Henry Wasser, all three of whom worked conscientiously on the Editorial Committee. We are also grateful to Guy Neave, Editor of Higher Education Policy, for making this special issue possible. 